Revista Eletrônica do Mestrado em Educação Ambienta1

\title{
Pertencimento: um elo conectivo entre o ser humano, a sociedade e a natureza
}

\author{
Débora Gisele Graúdo dos Santos ${ }^{1}$ \\ Universidade Federal Rural do Rio de Janeiro \\ ORCID https://orcid.org/0000-0002-7455-1054 \\ Mauro Guimarães ${ }^{2}$ \\ Universidade Federal Rural do Rio de Janeiro \\ ORCID https://orcid.org/0000-0002-4158-313X
}

\begin{abstract}
Resumo: O presente artigo é um recorte da dissertação de mestrado "A relação entre o sentimento de pertencimento e a educação ambiental" e busca problematizar o sentimento de pertencimento como um elemento estruturante para o processo formativo de Educação Ambiental. As reflexões deste estudo representam um olhar (entre muitos olhares possíveis) pautado em emoções que constituem a identidade do nosso "ser" humano e natural. Ao longo do trabalho destacamos elementos que nos ajudam a pensar e repensar os princípios formativos presentes na "ComVivência Pedagógica", como: a postura conectiva; a intencionalidade transformadora; a promoção da reflexão crítica; a indignação ética; a desestabilização criativa; e ressaltamos a emoção do pertencer - fundamentais na desconstrução de sentidos hegemônicos da modernidade e no reencontro com o natural.
\end{abstract}

Palavras-chave: Pertencimento; ComVivência Pedagógica; Reencontro com o natural.

\section{Pertenencia: un enlace conectivo entre el ser humano, la sociedad y la naturaleza}

Resumen: Este artículo es un recorte de la tesis de maestría "La relación entre el sentimiento de pertenencia y la educación ambiental" y busca problematizar el sentimiento de pertenencia como elemento estructurante del proceso formativo de la Educación Ambiental. Las reflexiones de este estudio representan una mirada (entre muchas miradas posibles) basada en las emociones que constituyen la identidad de nuestro "ser" humano y natural. A lo largo del trabajo, destacamos elementos que nos ayudan a pensar y repensar los principios formativos presentes en la "ComVivência Pedagógica", tales como: la postura conectiva; la intencionalidad transformadora; la promoción de la reflexión crítica; la indignación ética; la desestabilización creativa; y enfatizamos

\footnotetext{
1 Mestra em Educação pelo Programa de Pós-Graduação em Educação, Contextos Contemporâneos e Demandas Populares (PPGEduc) da Universidade Federal Rural do Rio de Janeiro (UFRRJ). e-mail: deboragraudo@ gmail.com

${ }^{2}$ Doutor em Ciências Sociais pela Universidade Federal Rural do Rio de Janeiro (UFRRJ). Professor pesquisador do Programa de Pós-Graduação em Educação, Contextos Contemporâneos e Demandas Populares (PPGEduc) da Universidade Federal Rural do Rio de Janeiro (UFRRJ). e-mail: guimamauro@ @otmail.com
} 
la emoción de pertenencia - fundamental en la deconstrucción de los sentidos hegemónicos de la modernidad y en el reencuentro con lo natural.

Palabras-clave: Pertenencia; ComVivência Pedagógica; Reencuentro con lo natural.

\section{Belonging: a connective link between the human being, society and nature}

Abstract: This article is a cutout of the Master's thesis "The relationship between the feeling of belonging and environmental education" and seeks to problematize the feeling of belonging as a structuring element for the formative process of Environmental Education. The reflections of this study represent a look (among many possible looks) based on emotions that constitute the identity of our human and natural "being". Throughout the work we highlight elements that help us think and rethink the formative principles present in the "Pedagogical ComVivência", such as: the connective posture; the transforming intentionality; the promotion of critical reflection; the ethical indignation; the creative destabilization; and we emphasize the emotion of belonging - fundamental in the deconstruction of hegemonic senses of modernity and in the re-encounter with the natural.

Keywords: Belonging; Pedagogical ComVivência; Re-encounter with the natural.

\section{Introdução}

Embora a ideia de dominação da natureza já existisse antes mesmo da modernidade, a disjunção entre o ser humano e a natureza foi se intensificando no decorrer do desenvolvimento da sociedade moderna. Com o aumento da busca do "eu" (superficial e individualista) em detrimento do "outro" (na coletividade), a "racionalização do ser" (NABAES, 2015) acreditou que o progresso, através da ciência e da tecnologia, seria a salvação para todos os problemas. Entretanto, por mais que progressos inéditos surgissem, o projeto de vida moderna não se realizou para todos, nem mesmo na Europa. Os problemas se acumularam e as contradições tornaram-se cada vez mais evidentes.

O paradigma ${ }^{3}$ moderno entrou em crise (CARVALHO, 2012) e novos conflitos surgiram diante de relações hierarquizadas entre seres humanos e entre seres humanos e a natureza. De acordo com Leff (2016, p.19-20), “a crise ambiental é uma crise civilizatória, uma crise dos modos de compreensão, de cognição e de produção de conhecimentos que, através de sua hegemonia dominante, construíram um mundo insustentável”. Nesse contexto, a busca pelo que o autor interessantemente aponta como FIB (Felicidade Interna Bruta) é enraizada na economia moral do "viver bem".

O racionalismo cartesiano-newtoniano embasou o pensamento científico e durante muito tempo foi considerado o único meio válido para se chegar ao conhecimento. É importante ressaltar que o "conhecimento não é o produto apenas de nossa capacidade de reflexão interna, mas de nossa interação com o meio que nos cerca e da forma como

\footnotetext{
${ }^{3}$ A palavra paradigma significa modelo ou padrão. Paradigmas, de acordo com Edgar Morin (apud GUIMARÃES, 2004, p. 29), são "estruturas de pensamento que de modo inconsciente comandam nosso discurso".
} 
atribuímos significados às coisas" (ANDRADE, 2012, p. 119). Para Maturana (2004), o conhecimento surge nas relações (no fluir do nosso viver) e no entrelaçamento do emocionar com o agir. Somos seres inacabados (FREIRE, 1996) e, claro, complexos. Quanto mais complexos, mais autônomos ${ }^{4}$ e mais dependentes das relações que estabelecemos com os outros seres e com o universo.

Para pensar fora dos moldes da modernidade é necessário transcender os modos dominantes de compreensão do mundo (LEFF, 2016). É importante refletirmos sobre o sentimento de pertencer ao natural (pertencemos à natureza?), rompendo com paradigmas cartesianos e superando dualidades como: o ser humano e o universo; a natureza e a sociedade; a razão e a emoção; o observador e o ato de observar. Práticas pedagógicas que fragmentam o todo, representam uma "armadilha paradigmática" (GUIMARÃES,2006), definida como uma limitação compreensiva atrelada a uma incapacidade discursiva muitas vezes é uma boa intenção, mas uma prática ingênua. Na ruptura da armadilha paradigmática, utilizando a ideia do "caminho único" - também descrito por Guimarães (2006) - é fundamental um movimento coletivo gerador de sinergia $(1 \text { com } 1>2)^{5}$ contra a correnteza que nos empurra sempre na mesma direção.

Trein (2008) alerta que a compreensão reducionista das relações intrínsecas do nosso viver representa um obstáculo no enfrentamento da problemática socioambiental. Por isso, acreditamos que práticas pedagógicas que estimulem o "reencontro com o natural”, a partir de outras relações (que não são as relações de dominação, opressão e poder estabelecidas na nossa sociedade), podem fazer aflorar dimensões rompidas no decorrer do desenvolvimento capitalista, como a amorosidade, descrita por Paulo Freire (1996) e Humberto Maturana (2002). Entendendo o amor como uma força conectiva que no fluir do nosso viver nos une ao todo; elemento essencial no processo educativo. A falta de amor consigo, com o outro e com o universo (MATURANA, 2002) reflete nos problemas socioambientais atuais, historicamente enraizados na lógica perversa do sistema capitalista. Quando estabelecemos relações amorosas, dialógicas e horizontais

\footnotetext{
${ }^{4}$ A autonomia é individual, porém para além da individualidade. De acordo com Maturana e Varela (1995), um sistema vivo é autônomo, pois está constantemente se autoproduzindo/autoregulando, ao mesmo tempo em que é coletivo, devido a ininterrupta interação com o meio. Ultrapassando o conceito biológico, compreendemos que a autonomia e a coletividade são mutualmente dependentes.

${ }^{5}$ Sinergia é a força resultante da cooperação. De acordo com Guimarães (2004), o movimento coletivo (junto em conjunto) que gera uma sinergia $(1 \mathrm{com} 1>2)$ é qualitativamente superior ao somatório de ações individuais $(1+1=2)$. Sem desconsiderar, é claro, o protagonismo como fortalecedor do movimento dinâmico das relações.

${ }^{6}$ O termo "Reencontro com o Natural" é proposto na Dissertação de Mestrado "Experiências de "ComVivência Pedagógica" a partir de outras epistemologias em processos formativos de educadores ambientais" (GRANIER, 2017), compreendendo que a disjunção sociedade e natureza não se trata de uma perda do natural, mas sim de um afastamento. Sendo assim, a autora aponta para a necessidade de um reencontro.
} 
promovemos espaços perturbadores, isto é, espaços de interação e reflexão, que nos desestabilizam e estimulam a auto-organização e, dependendo do grau de complexidade, a transformação.

A indissociabilidade do ser humano histórico-biológico-social (permeado por contradições, embates e negociações) é fundamental para a compreensão do pertencimento em uma realidade complexa e autopoiética ${ }^{7}$. A partir desse olhar, o objetivo deste trabalho é problematizar o "sentimento de pertencimento" como um elemento estruturante para o processo formativo de Educação Ambiental (EA), enfatizando a necessidade do ser humano compreender-se natureza.

\section{O sentimento de pertencimento no contexto das relações}

Não há ainda uma definição única do pertencimento, mas destacamos algumas autoras, como: Sandra Lestinge (2004) $)^{8}$, Lais Sá $(2005)^{9}$, Cláudia Cousin $(2010)^{10}$, Suzane Vieira (2012) ${ }^{11}$ e Daniela Pieper (2012) $)^{12}$, que trabalharam a relação entre o Pertencimento e a EA, representando caminhos possíveis para a compreensão do pertencer como um valor social, moral, estético, político, cultural, religioso e também ambiental. É claro que uma delimitação rígida seria simplista diante da complexidade que engloba o sentimento de pertencimento. Por isso, não pretendemos esgotar os argumentos sobre esse fenômeno, mas pensá-lo como uma possibilidade na construção de novas relações entre o eu, o outro e o universo.

O pertencimento possui um sentido ontológico, de pertencer e ser (LESTINGE, 2004; VIEIRA, 2012). De acordo com Sá (2005), em consequência do modelo de desenvolvimento capitalista, estabelecemos relações de dominação e exploração artificiais no/com o mundo e assim nos esquecemos e nos afastamos da capacidade intrínseca do ser humano de pertencer. O pertencimento no reencontro com o natural intensifica sentimentos que nos integram ao todo, como a amorosidade, o diálogo, a coletividade, a solidariedade e

\footnotetext{
${ }^{7}$ O conceito de autopoiesis, proposto por Maturana e Varela em 1995, descreve o princípio complementar entre a autonomia e a coletividade. Biologicamente, é o fato de uma célula possuir organização autopoiética que a caracteriza como autônoma em espaços de interatividade (MATURANA \& VARELA, 1995).

${ }^{8}$ Tese de Doutorado: "Olhares de educadores ambientais para estudos do meio e pertencimento".

9 Artigo: "Pertencimento". In: FERRARO JÚNIOR, L. A. (Org.). Encontros e caminhos: formação de educadoras(es) ambientais e coletivos educadores.

${ }^{10}$ Tese de Doutorado: "Pertencer ao navegar, agir e narrar: a formação de educadores ambientais".

${ }^{11}$ Tese de Doutorado: "O sentimento de pertencimento na formação do pedagogo: o curso de Pedagogia da FURG no contexto das novas Diretrizes Curriculares".

12 Dissertação de Mestrado: "Representações às margens do São Gonçalo: o pertencimento e sustentabilidade na perspectiva da Educação Ambiental da UFPEL - Um estudo de um processo de formação/capitação dos servidores".
} 
tantos outros que potencializam a construção de identidade, a construção da alteridade e as relações múltiplas.

Nabaes (2015) aponta a "racionalidade instrumental" como orientadora das formas de ser-no-mundo. Para a autora, no contexto do capitalismo, o ter tornou-se a base estrutural do ser. A partir da Revolução Técnico-Científica-Informacional, não apenas os meios de produção e consumo (como a obsolescência programada) foram transformados, mas também as relações sociais, ambientais e culturais. Um exemplo é a internet e as diferentes redes sociais (Facebook, WhatsApp, Twitter, Instagram, YouTube, Snapchat, etc.) que modificaram a noção de tempo/espaço - capaz de conectar pessoas em todos os lugares do mundo e ao mesmo tempo desconectar pessoas ao seu redor. Conforme aponta Barcelos (2012, p. 19): "paradoxalmente, ao mesmo tempo em que estamos todos juntos, no mesmo planeta, nunca estivemos tão separados".

Também podemos mencionar o surgimento da Biotecnologia, a descoberta do genoma humano, a invenção robótica e outros, que não apenas evidenciam a potência científica e tecnológica como determinam nosso estilo de vida, organização e valores (CAPRA, 2006). É óbvio que devemos usar a ciência e a tecnologia, de fato ambas foram e são importantes em diversas áreas do conhecimento, como na medicina, por exemplo. Porém, é fundamental um redirecionamento radical para que não sejam meros instrumentos de maximização dos lucros.

Nesse contexto, Leff (2011) enfatiza a necessidade da construção de uma nova racionalidade, uma "racionalidade ambiental". Uma mudança radical de pensamentos, percepções e valores a partir de uma concepção sistêmica da realidade. Essa concepção sistêmica compreende o mundo em termos de relações e integrações (CAPRA, 2006) parte-todo e todo-parte. Na tentativa de reintegração ao natural, algumas propostas educativas defendem o contato direto com a natureza e pregam o retorno ao simples e essencial, tanto tecnológico como espiritual. Porém, em uma visão romântica e ingênua, reforçando e perpetuando o dualismo "ser humano versus natureza". Nessa perspectiva, a natureza é fortemente associada à ideia de fauna e flora; um ambiente urbano, raramente, é considerado natureza; e o ser humano, quase sempre, é externo ao natural.

Carvalho (2012) aponta para duas visões historicamente construídas de relação e compreensão da natureza que ultrapassaram seus contextos de origem e permanecem enraizadas nos dias atuais, são elas: a natureza percebida ora como objeto de dominação e exploração - fonte inesgotável de recursos; ora como um lugar intocável, de mera contemplação - sem ação antrópica. Em ambos percebemos a ideia do ser humano externo 
a natureza, o humano não natural. Para Morin (2003) esse "reencontro" (descrito também como "religação") é a chave para a transformação. E é essa transformação que defendemos no reencontro com o natural: a transformação das relações.

\section{O pertencimento no reencontro com o natural}

Nossas ideias ou conceitos organizam o mundo, tornando-o inteligível e familiar. São como lentes que nos fazem ver isso e não aquilo e nos guiam em meio à enorme complexidade e imprevisibilidade da vida. Acontece que, quando usamos óculos por muito tempo, a lente acaba fazendo parte de nossa visão a ponto de esquecermos que ela continua lá, entre nós e o que vemos, entre os olhos e a paisagem. (CARVALHO, 2012, p. 33)

Renovar as nossas lentes é o que nos propõe Carvalho (2012). A realidade emerge com a ação do observador, o que ouvimos ou lemos é fruto das relações estabelecidas (teóricas, técnicas, ideológicas, entre outras) ditas/escritas a partir de uma lente, a lente de quem observa. $O$ que não significa dizer que não existam outros olhares igualmente válidos.Por isso, entre muitos olhares possíveis, neste trabalho, apresentamos alguns indicativos da relação entre a construção do sentimento de pertencimento e o processo formativo para a consolidação de uma EA crítica, emancipatória e também transformadora, elaborados a partir do movimento conjunto do Grupo de Estudo e Pesquisa em Educação Ambiental, Diversidade e Sustentabilidade (GEPEADS/PPGEduc/UFRRJ) e das reflexões finais resultantes da análise e interpretação dos dados coletados ${ }^{13}$ na Dissertação da autora.

Elementos como amorosidade, dialogicidade, acolhimento, solidariedade, respeito, vivência, convivência, cooperação, reflexão, identidade, tempo e criatividade, nos ajudam a pensar e repensar sobre o sentimento de pertencimento. Fundamentados nos nossos referenciais teóricos, nos estudos e publicações anteriores do nosso grupo de pesquisa, alguns princípios formativos presentes na "ComVivência Pedagógica" vêm sendo formulados, são eles: a postura conectiva; a intencionalidade transformadora; a promoção da reflexão crítica; a indignação ética e a desestabilização criativa, como potencializadores de práticas de transformação social, pautadas em emoções que constituem o nosso "ser" humano e natural.

\footnotetext{
${ }^{13}$ Os dados foram coletados em uma escola pública do entorno da Unidade de Conservação de Tinguá, localizada no Município de Nova Iguaçu, no Estado do Rio de Janeiro, através da observação participante no espaço escolar e das narrativas autobiográficas dos professores participantes. Posteriormente, foram analisados seguindo o Método de Interpretação de Sentidos, de Gomes et al. (2005).
}

Rev. Eletrônica Mestr. Educ. Ambient. Rio Grande, v. 37, n. 3, p. 208-223, mai./ago. 2020. 
O pensamento moderno dicotomizou a razão e a emoção; de acordo com Maturana (2002, p.15), "não vemos o entrelaçamento cotidiano entre razão e emoção, que constitui nosso viver humano, e não nos damos conta de que todo sistema racional tem um fundamento emocional". Para o autor a emoção determina nosso "domínio de ação", isto é, nossas ações são guiadas pelas nossas emoções, sejam elas boas ou ruins. Por isso, Maturana descreve: "o amor é a emoção que constitui o domínio de ações em que nossas interações recorrentes com o outro fazem do outro um legítimo outro na convivência" (MATURANA, 2002, p. 22). O mesmo diferencia emoção de sentimento, afirmando que não necessariamente um sentimento gera uma ação. Nesse sentido, é fundamental que o sentimento de pertencer potencialize a emoção do pertencer, ou seja, a ação.

Pertencer, para além da lógica simplista e reducionista, requer do educador uma postura conectiva consigo mesmo, com o outro e com o universo. Lestinge (2004) utiliza a expressão "ser-com-os-outros" de Heidegger. Essa conexão só pode ocorrer com o rompimento das relações culturais e historicamente construídas de poder, dominação e opressão presentes na sociedade moderna. Para a postura conectiva torna-se fundamental a compreensão da complexidade parte-todo e da complementaridade entre autonomia e coletividade. Não podemos ignorar que somos seres formados por conexões múltiplas; somos natureza com singularidades que nos definem como espécie humana; somos ao mesmo tempo biológicos e sociais, emocionais e racionais (MORIN, 2000). Não podemos conhecer as partes sem conhecer o todo, muito menos conhecer o todo sem conhecer particularmente as partes, como descreve Morin (2000).

A autonomia e a coletividade possuem uma relação de interdependência a partir da perspectiva sistêmica, enquanto que na perspectiva da simplificação/redução, na maioria das vezes, são considerados meros conceitos antagônicos. De acordo com Gutiérrez e Prado (2013, p.20), "o êxito do sistema como um todo depende do êxito de cada parte e, ao contrário, o êxito de cada parte depende do êxito do sistema como um todo", compreender essa relação de interdependência representa um passo importante na postura conectiva. No contexto escolar, já nos anos iniciais de ensino, aprendemos a compartimentar e não a unir as diversas áreas do conhecimento, e com isso, conforme aponta Morin (2000), o mundo nos parece um grande quebra-cabeça com peças incompreensíveis e não percebemos o que está tecido junto, isto é, a complexidade insimplificável. É comum que os educadores, mesmo bem intencionados, ao trabalharem as questões ambientais reproduzam práticas que reforçam a racionalidade hegemônica (GUIMARÃES, 2013). 
Por exemplo, quase sempre, as questões ambientais são reduzidas aos aspectos físicos e biológicos do ambiente (rios, solos, clima, fauna e flora), os fatores sociais, históricos e culturais são invisibilizados. “(...) Nos projetos de educação ambiental raramente são tratados a extinção e/ou o aniquilamento de culturas, de sentimentos, de gestos de solidariedade" (BARCELOS, 2012, p. 48) ${ }^{14}$. Corroborando com o autor, entre as narrativas autobiográficas transcritas e analisadas em nossas investigações, em conjunto com as observações de campo, os dados coletados - constituídos por sentimentos, memórias e fragmentos do cotidiano dos professores participantes - revelam que ainda que os docentes possuam uma visão crítica sobre as questões ambientais, em suas práticas pedagógicas no dia a dia da sala de aula, permanecem imobilizados diante de dificuldades que apontam: falta de tempo, falta de suporte, falta de investimento, falta de qualificação e/ou falta de reconhecimento. E assim, as questões ambientais ainda ocorrem de forma pontual na escola, como no "dia do meio ambiente" ou no "dia da água" ou até mesmo no "dia da árvore". Reforçando o que Guimarães (2004) descreve como "armadilha paradigmática".

Romper com a "armadilha paradigmática" é um dos objetivos centrais da proposta de formação por uma Educação Ambiental crítica, como descreve Guimarães e Granier (2017). Nesse sentido, a EA crítica é atrelada a intencionalidade transformadora. Compreendemos que a ação educativa não é neutra, mas permeada por sentimentos, crenças, desejos, teorias, valores e/ou outros estados intencionais éticos, filosóficos, políticos e culturais. Logo, sendo a EA crítica uma ação intencional de ruptura, podemos dizer que está atrelada a promoção da reflexão crítica. Com base nos estudos Freireanos, a reflexão crítica que se dá pela práxis, isto é, na relação reflexão-ação-reflexão, possibilita ao educador ambiental uma intervenção educacional processual, ultrapassando o "agir no automático" (GUIMARÃES, 2015). Diferentemente da intervenção pontual (ainda que sequencial), a intervenção processual (no sentido de movimento coletivo conjunto) cria uma sinergia $(1$ com $1>2$ ), como descreve Guimarães (2004). Esse movimento de ruptura com as relações verticais tradicionais de ensino propicia outras relações, relações horizontais e dialógicas.

\footnotetext{
${ }^{14}$ A partir de uma pesquisa com aproximadamente 500 professores da educação básica na rede pública, entre 2001 e 2005, Valdo Barcelos (2012) observou que as concepções que professores têm sobre a EA influenciam diretamente suas práticas pedagógicas. Para o autor os professores, muitas vezes, esperam uma fórmula/uma receita "de fora", desacreditando que também podem trabalhar com as questões ambientais; talvez como consequência da desarticulação interdisciplinar das iniciativas de EA, que privilegiam determinadas áreas do conhecimento e reafirmam a ideia fortemente enraizada nas escolas de que a inserção da EA é responsabilidade e quase que exclusividade dos professores de Ciências e Biologia.
}

Rev. Eletrônica Mestr. Educ. Ambient. Rio Grande, v. 37, n. 3, p. 208-223, mai./ago. 2020. 
Guimarães (2004) aponta que a ação de educar se dá na relação. Para Salke (apud GUTIÉRREZ \& PRADO, 2013, p.19), “a relação é o fenômeno mais importante do universo", sendo assim, é fundamental compreender a relação que se estabelece no contexto empírico da construção do sentimento de pertencimento. Grün (2010) afirma que a nossa "pertença" está diretamente ligada à nossa compreensão de mundo. Por isso, os conflitos socioambientais só podem ser resolvidos através dos "sentidos existenciais" (LEFF, 2011, p. 318), visto que a percepção de tais conflitos, segundo Barcelos (2012), são criações autônomas e ao mesmo tempo dependentes do nosso existir. Diante disso, compreendemos que o sentimento de pertencimento compõe a identidade do educador, em especial do educador ambiental, é a essência do nosso "ser" humano. O pertencer, mesmo que possa estar esquecido/invisibilizado na sociedade atual, representa um sentido existencial, uma filosofia de vida, que pode ser aflorado a partir da experiência relacional, fundamentados em atitudes básicas de solidariedade, cooperação e diálogo.

Na postura conectiva o dialógico enseja um ambiente educativo onde as emoções (como o amor) possam ser vivenciadas. Para Barcelos e Maders (2016, p. 31) "vivemos em um ambiente cultural que fala o tempo todo do amor, contudo, as nossas ações fazem a negação deste amor". De acordo com os autores, nos acostumamos a falar sobre, a teorizar sobre, mas temos dificuldades de viver esse amor. Interessantemente, Catherine Walsh (2009) compreende o amor:

Como aparato político e existencial, como componente central de uma consciência dissidente e criativamente insurgente que pode intervir (e insurgir) tanto no interior como nas relações modernas-coloniaisneoliberais que mantêm a dominação e desumanização. (Ibidem, p. 39, grifo da autora).

Inspirados pela autora, consideramos que práticas pedagógicas pautadas na amorosidade potencializam o "in-surgir", o "re-existir" e o "re-viver" (WALSH, 2009, p. 37), fundamentais para a construção de ambientes educativos radicais (não no sentido de radicalismo, mas no sentido de buscar raízes). O processo formativo de EA passa pela radicalidade (GUIMARÃES \& GRANIER, 2017). De acordo com Morin (2003), frequentemente, os problemas da educação são quantificados como a necessidade de mais ou menos algo; mais conteúdos e menos rigidez, por exemplo, o que não significa que não sejam importantes de serem pensados, entretanto são modificações pontuais e reducionistas que camuflam a verdadeira necessidade: a "reforma de pensamento". O autor revela que no enfrentamento das incertezas a reforma do pensamento é paradigmática. E ressalta que 
nenhuma grande reforma é feita de uma só vez, a mudança começa por uma minoria que sente necessidade de mudar, por isso:

É preciso saber começar, e o começo só pode ser desviante e marginal. [...]. E a reforma também começará de maneira periférica e marginal. Como sempre, a iniciativa só pode partir de uma minoria, a princípio incompreendida, às vezes perseguida. Depois, a ideia é disseminada e, quando se difunde, torna-se uma força atuante (MORIN, 2003, p. 101).

Para a reforma do pensamento a radicalidade torna-se fundante. Impregnados do/pelo desejo de mudança, educadores militantes radicais da causa socioambiental, transformados e transformadores, dinamizadores de movimentos contra hegemônicos em suas esferas de atuação, disseminam novas relações e formas de viver (GUIMARÃES \& GRANIER, 2017). Essa força em oposição aos paradigmas hegemônicos da modernidade é entendida como resistência. O "imprinting cultural" (termo proposto por Konrad Lorenz), de acordo com Morin (2000), marca os seres humanos desde o nascimento e prossegue ao longo da vida, normalizando um estado de conformismo, um conformismo cognitivo, nos fazendo acreditar que "as coisas sempre foram assim", e por isso, determinações econômicas, políticas, sociais e culturais são incontestáveis, como um "caminho único" (GUIMARÃES, 2006). Neste sentido, a resistência representa uma emoção essencial contra nossas próprias inércias existenciais. Cabe ressaltar que resistir está intimamente atrelado com o refletir criticamente.

Sem uma reflexão crítica, os paradigmas tendem a induzir como "normal" algo preestabelecido, consolidado por uma racionalidade dominante. Considerando a escola como uma instituição social em disputa, como descreve Guimarães e Pinto (2017), torna-se fundamental no movimento contra hegemônico a indignação ética. Diante do cenário de injustiças que vivemos, a indignação ética impulsiona o enfrentamento das "cegueiras" impostas pela sociedade capitalista, proporcionando assim a "ousadia para inovar" (GUIMARÃES, 2004). A ética é inseparável da prática educativa e precisa ser vivenciada a partir da reflexão crítica (FREIRE, 1996). Sendo a história tempo de possibilidade e não de determinismo, vale destacarmos um clássico Freireano:

[...] inacabado, sei que sou um ser condicionado, mas, consciente do inacabamento, sei que posso ir mais além dele. Esta é a diferença profunda entre o ser condicionado e o ser determinado. A diferença entre $\mathrm{o}$ inacabado que não se sabe como tal e o inacabado que histórica e socialmente alcançou a possibilidade de saber-se inacabado. (FREIRE, 1996, p. 23)

Rev. Eletrônica Mestr. Educ. Ambient. Rio Grande, v. 37, n. 3, p. 208-223, mai./ago. 2020. 
Somos seres inacabados, além disso, Paulo Freire alerta que precisamos reconhecer que somos seres condicionados, mas capazes de ultrapassar o próprio condicionamento. Portanto, retrocessos políticos e econômicos no contexto brasileiro e mundial podem até nos condicionar, porém não podem nos imobilizar, não devemos ser apáticos frente a esse cenário, ainda que cruelmente estejamos tensionados entre "o feijão e o sonho"15. Daí a importância da indignação ética. Cabe ressaltar que "não há ética nem política possível onde não há história como processo constitutivo que forma os padrões culturais que orientam nosso agir moral" (GRÜN, 2010, p. 106). Freire é enfático sobre a importância de intervir e lutar; para o autor:

Não há prática social mais política que a prática educativa. Com efeito, a educação pode ocultar a realidade da dominação e da alienação ou pode, pelo contrário, denunciá-las, anunciar outros caminhos, convertendo-se assim numa ferramenta emancipatória. $O$ oposto de intervenção é adaptação, é acomodar-se, ou simplesmente adaptar-se a uma realidade sem questioná-la. (FREIRE apud WALSH, 2009, p. 29)

A intervenção que nos propõe Freire perpassa pela desestabilização criativa. Sendo a criatividade uma ação autônoma e coletiva (MATURANA, 2002), em relação às questões socioambientais, representa também uma possibilidade propulsora na ruptura da armadilha paradigmática. Na Biologia do Conhecer ${ }^{16}$, criar é uma atividade biológica cognitiva e, ao mesmo tempo, um fenômeno social. Já, desestabilizar quer dizer estar aberto ao novo, sair da zona de conforto. Compreendemos que a desestabilização ocorre a partir de um estranhamento inicial que permite uma desconstrução e posteriormente uma (re)construção que, consequentemente, gera uma nova (des)(re)construção de nossas percepções e práticas. Cabe ressaltar que entendemos que a desestabilização criativa não é espontânea, mas ocasionada pela reflexão crítica e pela intencionalidade transformadora. Como aponta Pellanda (2003), baseada nos trabalhos de Maturana e Varela sobre acoplamento estrutural autopoiético, perturbações (que podemos descrever como interações criativas) podem desencadear um efeito, uma transformação, promovendo o novo por meio de outras relações consigo e com o outro (social e natural).

Por todos os indicativos já expostos, entendemos que "educar para pertencer" (LESTINGE, 2004) é uma necessidade urgente. Pertencer a partir de uma perspectiva

\footnotetext{
${ }^{15}$ Livro de Orígenes Lessa, O feijão e o sonho (1938). A narração questiona os conflitos entre o sustento familiar e os anseios da alma. Citado por um dos professores participantes da pesquisa.

${ }^{16}$ Teoria proposta por Humberto Maturana, em colaboração com Francisco Varela (1995).
} 
complexa, autopoiética, constante e dialética contrapõe o pertencer individualista e reducionista enraizado na sociedade moderna. Não defendemos um discurso ideológico antimodernista, não se trata de negar o valor do conhecimento científico e tecnológico, mas compreendê-lo criticamente, como defende Carvalho (2012). Fundamentado na EA crítica, o pertencimento possui um sentido ontológico, “pertencer e ser" (LESTINGE, 2004; VIEIRA, 2012). Por isso, pertencemos à humanidade porque somos humanos e pertencemos à natureza porque somos natureza. Nessa complexa teia da vida, o sentimento de pertencimento é compreendido como um elo conectivo que nos liga ao todo, capaz de potencializar a autonomia e a coletividade, necessária para a construção da identidade (o eu), a construção da alteridade (o outro) e as interações de relações múltiplas (o universo).

A relação entre o sentimento de pertencimento e a EA só pode ser compreendida por meio de novas "lentes", conforme apontado por Carvalho (2012). Essa relação representa um movimento de transição paradigmática na desconstrução de sentidos hegemônicos da modernidade. Pertencer é uma filosofia de vida em oposição à lógica do modelo de desenvolvimento capitalista de ser-e-estar-no-mundo. Por possuir um arcabouço fenomenológico-existencialista, o sentimento de pertencimento - seja como espaço territorial e/ou como dimensão concreto-abstrata ${ }^{17}$ (LESTINGE, 2004) - é importante para pensarmos em propostas de EA numa perspectiva crítica e transformadora. Aqui apresentamos o exercício da emoção do pertencer como um eixo transversal formativo em complementaridade direta à postura conectiva; a intencionalidade transformadora; a reflexão crítica; a indignação ética e a desestabilização criativa.

Evidentemente é um grande desafio transformar os princípios apontados em atitudes cotidianas, pois, como afirma Barcelos (2012), não há alternativa sem o rompimento com o ideário moderno de sociedade. Mas, conforme ressaltamos, o fazer diferente requer um esforço e, geralmente, começa através de uma minoria motivada por questões diversas. Um passo essencial nesse caminho de ruptura com os paradigmas disjuntivos é a prática pedagógica dinamizadora de ambientes educativos amorosos, dialógicos e horizontais, entendendo ambiente educativo para além do espaço físico escolar, como descreve Guimarães (2004), mas como o movimento complexo das relações entre o ser humano, a sociedade e a natureza, no fluir do nosso viver e no entrelaçamento do emocionar com o agir.

\footnotetext{
${ }^{17}$ Segundo Lestinge (2004), o conceito de pertencimento pode nos remeter ao sentimento por um espaço territorial (enraizamento) e/ou ao sentimento de inserção e integração a um todo maior (dimensão concreto-abstrata). Para este estudo, buscamos compreender o sentimento de pertencimento à humanidade e à natureza, como um todo complementar e complexo. Sem desconsiderar, é claro, o espaço territorial como o lócus da experiência e do despertar das emoções.
} 


\section{Considerações finais}

Ao longo deste trabalho - de construção e desconstrução, de certezas e incertezas, de emoções e razões -, buscamos compreender e problematizar o sentimento de pertencimento como um elemento estruturante para o processo formativo de EA. Em um exercício reflexivo constante, ao dialogar com nossa própria trajetória de vida, que por diversas vezes somos induzidos e conduzidos a acreditar que a razão é de fato a solução para todos os problemas, compreendemos o quão difícil é pertencer. Difícil, mas não impossível! Difícil porque exige de nós um esforço contra as "armadilhas paradigmáticas". Pertencer no sentido existencial, como descrevemos, para além da lógica individualista, simplista e reducionista, requer um movimento contra a correnteza que nos aprisiona no caminho único. Defendemos o pertencer no sentido amplo, ao todo, à humanidade e à natureza. Esse sentimento de pertencimento pode potencializar a emoção do pertencer. Compreendendo que a emoção gera uma ação.

O exercício da "emoção do pertencer", que acreditamos ser fundamental na desconstrução de sentidos hegemônicos da modernidade, foi apresentado como um eixo transversal de formação complementar aos princípios formativos presentes "ComVivência Pedagógica". A emoção do pertencer é inerente a nossa essência e pode ser aflorada a partir de atitudes básicas que redirecionem de forma radical nossos sentidos existenciais. $\mathrm{O}$ que exige de nós, seres autônomo-coletivos, que vivemos em ritmos frenéticos, tempos de "parada" (dos cinco sentidos), algo que parecia impossível antes da pandemia do Covid-19. Porém, diante da necessidade do isolamento social, percebemos o quanto o tempo pode ser relativo. O cenário atual nos proporcionou o tempo de refletir, de sentir, de escutar, de ver, de conviver, de aprender, de reinventar e de amar. Esse "tempo de parada" representa uma rara e importante oportunidade de questionamento do desenvolvimento socioeconômico, um possível passo na transformação individual-coletiva e no despertar para o pertencer. $\mathrm{O}$ pertencer familiar, comunitário, humanitário e planetário.

Pensar a relação entre o sentimento de pertencimento e a educação ambiental nos permitiu pensar em práticas educativas de transformação socioambiental, pautadas em emoções que constituem a identidade do nosso "ser" humano e natural. Diante da complexidade do pertencimento, achamos reducionista delimitá-lo, categorizá-lo, mas exploramos elementos que nos ajudam a compreendê-lo, como a amorosidade, a solidariedade, a cooperação, o respeito, o cuidado, entre outras sensações. Então, 
conseguimos entender o sentimento de pertencimento como um elo conectivo entre o ser humano, a sociedade e a natureza. Essa conexão é capaz de potencializar a construção do eu, do outro e do universo, por meio de interações múltiplas. Por meio dessas contribuições epistemológicas esperamos instigar outros pesquisadores na desconstrução do pensado, para pensar o ainda não pensado e repensar o já pensado, como nos inspira Paulo Freire, na busca de novos caminhos formativos.

\section{Referências}

ANDRADE, Claudia Castro de. A fenomenologia da percepção a partir da autopoiesis de Humberto Maturana e Francisco Varela. Revista de Filosofia, v. 6, n. 2, p. 98-121, 2012.

BARCELOS, Valdo. Educação ambiental: sobre princípios, metodologias e atitudes. 4. ed. Petrópolis, RJ: Vozes, 2012.

BARCELOS, Valdo; MADERS, Sandra. Humberto Maturana e a Educação: educar no amor e na liberdade. Santa Maria: Editora e Gráfica Caxias, 2016.

CAPRA, Fritjof. O ponto de mutação. São Paulo: Cultrix, 2006.

CARVALHO, Isabel Cristina de Moura. Educação ambiental: a formação do sujeito ecológico. 6. ed. São Paulo: Cortez, 2012.

FREIRE, Paulo. Pedagogia da autonomia: saberes necessários à prática educativa. São Paulo: Paz e Terra, 1996.

GOMES, Romeu; SOUZA, Edinilsa Ramos de; MINAYO, Maria Cecília de Souza; SILVA, Cláudio Felipe Ribeiro da. Organização, processamento, análise e interpretação de dados: o desafio da triangulação. In: MINAYO, Maria Cecília de Souza; ASSIS, Simone Gonçalves de; SOUZA, Edinilsa Ramos de (Orgs.). Avaliação por triangulação de métodos: abordagem de programas sociais. Rio de Janeiro: Fiocruz, p. 185-221, 2005.

GRANIER, Noeli Borek. Experiências de "ComVivência Pedagógica" a partir de outras epistemologias em processos formativos de educadores ambientais. 2017. 167f. Dissertação (Mestrado em Educação) - Programa de Pós-Graduação em Educação, Contextos Contemporâneos e Demandas Populares, Universidade Federal Rural do Rio de Janeiro, 2017.

GRÜN, Mauro. Ética e educação ambiental: a conexão necessária. 13. ed. Campinas, SP: Papirus, 2010.

GUIMARÃES, Mauro. A formação de educadores ambientais. Campinas: Papirus, 2004.

GUIMARÃES, Mauro. Armadilha paradigmática na educação ambiental. In: LOUREIRO, Carlos Frederico Bernardo; LAYRARGUES, Philippe Pomier; CASTRO, Ronaldo Souza 
de (Orgs.). Pensamento complexo, dialética e educação ambiental. São Paulo: Cortez, 2006.

GUIMARÃES, Mauro. Processos formativos do educador ambiental: a práxis de intervenção numa (com)vivência pedagógica. In: XVII ENDIPE - Encontro Nacional de Didática e Prática de Ensino (2014). E-book: CAVALCANTE, Maria Marina Dias et al. (Org.). Didática e a prática de ensino: diálogos sobre a escola, a formação de professores e a sociedade. Fortaleza/CE: EdUECE, 2015.

GUIMARÃES, Mauro. Por uma educação ambiental crítica na sociedade atual. Revista Margens Interdisciplinar, v. 7, n. 9, p. 11-22, 2013.

GUIMARÃES, Mauro; GRANIER, Noeli Borek. Educação ambiental e os processos formativos em tempos de crise. Revista Diálogo Educacional, v. 17, n. 55, p. 1574-1597, 2017.

GUIMARÃES, Mauro; PINTO, Vicente Paulo dos Santos. Alternativas para processos formativos de educação ambiental: a proposta da "(com)vivência pedagógica" diante de grandes e radicais desafios. Revista Eletrônica do Mestrado em Educação Ambiental. Rio Grande, Edição especial XVI Encontro Paranaense de Educação Ambiental, p. 118$131,2017$.

GUTIÉRREZ, Francisco; PRADO, Cruz. Ecopedagogia e cidade planetária. 3. ed. São Paulo: Cortez, 2013.

LEFF, Enrique. A aposta pela vida: imaginação sociológica e imaginários sociais nos territórios ambientais do Sul. Petrópolis, RJ: Vozes, 2016.

LEFF, Enrique. Complexidade, interdisciplinaridade e saber ambiental. Revista Olhar de professor, Ponta Grossa, 14(2), p. 309-335, 2011.

LESTINGE, Sandra Regina. Olhares de educadores ambientais para estudos do meio e pertencimento. 2004. 247f. Tese (Doutorado em Recursos Florestais) - Escola Superior de Agricultura Luiz de Queiroz, Piracicaba, 2004.

MATURANA, Humberto. Conferência: "Ética e desenvolvimento sustentável: caminhos para a construção de uma nova sociedade". Psicologia \& Sociedade, 16 (2), p. 102-110, 2004.

MATURANA, Humberto. Emoções e Linguagem na Educação e na Política. Belo Horizonte: Editora UFMG, 2002.

MATURANA, Humberto; VARELA, Francisco. A árvore do conhecimento. Editora Psy II, 1995.

MORIN, Edgar. A cabeça bem-feita: repensar a reforma, reformar o pensamento. 8. ed. Rio de Janeiro: Bertrand Brasil, 2003.

MORIN, Edgar. Os sete saberes necessários à educação do futuro. 2. ed. São Paulo: Cortez, 2000. 
NABAES, Thais de Oliveira. Leituras do Ser no horizonte da Racionalidade Ambiental: contribuições à Educação Ambiental. 2015. 132f. Tese (Doutorado em Educação Ambiental) - Programa de Pós-Graduação em Educação Ambiental da Universidade Federal do Rio Grande (FURG). Rio Grande, 2015.

PELLANDA, Nize Maria Campos. Conversações: modelo cibernético da constituição do conhecimento/realidade. Educação \& Sociedade, vol. 24, n. 85, p. 1377-1388, 2003.

SÁ, Lais Mourão. Pertencimento. In: FERRARO JÚNIOR, Luiz Antonio (Org.). Encontros e caminhos: formação de educadoras(es) ambientais e coletivos educadores. Brasília: MMA, Diretoria de Educação Ambiental, 2005.

TREIN, Eunice. A perspectiva crítica e emancipatória da Educação Ambiental. In: Educação Ambiental no Brasil - Salto para o futuro. Ministério da Educação. Ano XVIII, boletim 01, p. 41-45, 2008.

VIEIRA, Suzane da Rocha. O sentimento de pertencimento na formação do pedagogo: o curso de Pedagogia da FURG no contexto das novas Diretrizes Curriculares. 2012. 162f. Tese (Doutorado em Educação Ambiental). Programa de Pós-Graduação em Educação Ambiental da Universidade Federal do Rio Grande (FURG). Rio Grande, 2012.

WALSH, Catherine. Interculturalidade Crítica e Pedagogia Decolonial: in-surgir, re-existir e re-viver. In: CANDAU, Vera Maria Ferrão (Org.). Educação Intercultural na América Latina: entre concepções, tensões e propostas. p. 12-42, 2009.

Submetido em: 22-01-2020.

Publicado em: 21-08-2020. 